\title{
SENYAWA STEROID DARI KULIT BATANG Dysoxylum alliaceum DAN AKTIVITASNYA TERHADAP SEL KANKER PAYUDARA MCF-7
}

\author{
Ois Nurcahyanti ${ }^{*}$, Euis Julaeha \& Tri Mayanti
}

Departemen Kimia, Fakultas Matematika Dan Ilmu Pengetahuan Alam, Universitas Padjadjaran, Bandung Indonesia

*Alamat Korespodensi :ois.nurcahyanti@yahoo.com

\begin{abstract}
Abstrak: Dysoxylum merupakan salah satu genus yang memiliki metabolit sekunder dan aktivitas yang beragam, salah satu aktivitas yang menarik adalah mampu bertindak sebagai agen P-gp pada sel kanker payudara MCF-7. Kulit batang D.alliaceum dimaserasi berturut-turut dengan $n$-heksana, etil asetat dan metanol. Ekstrak $n$-heksan dipisahkan dan dimurnikan dengan berbagai teknik kromatografi dipandu dengan analisis kromatografi lapis tipis diperoleh dua senyawa stigmast-5-en3 $\beta$-ol (1), stigmasterol (2). Struktur kimia senyawa tersebut telah ditetapkan berdasarkan intrepretasi data-data spektroskopi dan dibandingkan dengan data spektra dari penelitian sebelumnya. Semua isolat senyawa dievaluasi aktivitas sitotoksiknya terhadap sel kanker payudara MCF-7. Senyawa 1 dan 2 dirujuk dari literatur menunjukkan aktivitas kuat dengan $\mathrm{IC}_{50} 8,65 \mu \mathrm{g} / \mathrm{mL}$.
\end{abstract}

Kata kunci: D.alliaceum, stigmasterol, $\beta$-sitosterol, sel MCF-7

Abstract: Dysoxylum is a genus that has secondary metabolites with biological aktivities, one of the interesting activities that is capable acted as agent of P-gp in MCF-7 breast cancer cells. Secondary metabolites from D.alliaceum already reported by Nishizawa et al., (1982). The bark of D.alliaceum extracted successively with $n$-hexane, ethyl acetate and methanol. The $n$-hexane extract was separated and purified using several chromatographic techniques asl well as guided by thn layer chromatografi analysis, and obtained four compounds stigmast-5-en-3 $\beta$-ol (1), stigmasterol (2). The chemical structure of these compounds has been determined based on spectroscopic interpretation and compared using data spectra from previous studies. All compounds were evaluated sitotoksik activity against MCF-7 breast cancer cell line. Compounds 1 and 2 showed weak cytotoxic activity $I_{50}>100$ $m g / m L$, compounds 1 and 2 showed strong activity with $I C_{50}$ of $8.65 \mathrm{ug} / \mathrm{mL}$ based on literature.

Keywords: Dysoxylum alliaceum, stigmasterol, $\beta$-sitosterol, MCF-7.

\section{PENDAHULUAN}

Dysoxylum merupakan salah satu genus dari Meliaceae yang terdiri atas \pm 80 spesies yang berada di Asia, Australia, dan sebelas spesies endemik di Cina (Mabberley 2008). Hingga sekarang ini, banyak senyawa golongan terpenoid, kroman alkaloid, limonoid, flavonoid, steroid, protolimonoid dan senyawa sulfur telah dilaporkan dan memiliki aktivitas yang sangat menarik (Najmuldeen, 2011).

Triterpenoid kumingianol diisolasi dari tanaman D.cumingianum dapat menghambat $\mathrm{P}$-gp pada sel kanker MCF-7 sehingga bisa dijadikan sebagai agen untuk kemoterapi (Wink et al. 2012). Menurut Mohanakumara et al., ( 2010) rohitukin pada Dysoxylum adalah prekursor flavopiridol, senyawa antikanker yang potensial. Flavopiridol pada D.binectariferum merupakan inhibitor dari MMP-2 dan MMP-9 pada sel kanker payudara MCF-7 (Tobin et al. 2012). Kulit batang D. binectariferum menghasilkan rohitukin yang sangat efektif terhadap ovarium dan kanker payudara (Lakshmi et al. 2007). Peneliti bermaksud untuk menggali metabolit yang sama, baru ataupun derivat dari jenis Dysoxylum lainnya yaitu Dysoxylum alliaceum. Laporan mengenai metabolit sekunder dari jenis D. alliaceum baru dilaporkan oleh Nishizawa et al., (1982) berupa senyawa (+)-8-hidroksi kalamenen yang diisolasi dari biji buah $D$. alliaceum.

\section{BAHAN DAN METODE}

Sampel yang digunakan dalam penelitian ini adalah bagian kulit batang D.alliaceum yang diperoleh dari Kebun Raya Bogor dan dideterminasi di Herbarium Bogorianse Pusat Penelitian Biologi LIPI, Bogor, Jawa Barat

\section{Bahan}

$n$-heksana, etil asetat, metanol, aseton, kloroform , air (aquades), silika gel $\mathrm{G}_{60}$ (70-230 mesh), ODS RP-18 $\mathrm{F}_{254}$, silika gel $\mathrm{GF}_{254}$ untuk pemisahan senyawa. lrutan $\mathrm{H}_{2} \mathrm{SO}_{4} 10 \%$ sebagai zat penampak noda, seperangkat alat uji sel MCF-7 (sel MCF-7, DMSO, MTT, dan PBS (Phosphate Buffer Saline). 


\section{Isolasi dan Penenetuan Struktur}

Proses ini terdiri dari tiga tahap, yaitu: ekstraksi kulit batang D.alliaceum pemisahan dan pemurnian isolat dari fraksi target serta karakterisasi isolat murni. Sampel berupa kulit batang D.alliaceum (3,5 $\mathrm{kg}$ ) dihaluskan kemudian diekstraksi dengan cara maserasi dengan menggunakan pelarut metanol. Ekstrak ini kemudian dipartisi berturut-turut dengan pelarut

$n$-heksana, etil asetat dan metanol. sehingga diperoleh ekstrak pekat $n$-heksana(65 g), etil asetat $(16 \mathrm{~g})$ dan metanol $(34 \mathrm{~g})$. Fraksi $n$-heksan (30 g) dipisahkan dengan kromatografi vakum cair (KVC) fase diam silika gel G60 sistem gradien $10 \%$ dengan $n$-heksana, etil asetat, dan metanol dihasilkan tujuh fraksi (A-G). Fraksi D (3,3 g) dilakukan pemisahan dengan kromatografi kolom (KK) $n$-heksan:EtOAc (8-2) menghasilkan lima fraksi (D1-D5). Fraksi D4 (1 g) dilakukan KK $n$ - heksan:EtOAc menghasilkan empat fraksi (D4A-D4D). sehingga diperoleh senyawa 1 (D4B) (76 mg). Fraksi E (1,1 g) dilakukan

KK

$n$ - heksan:EtOAc menghasilkan enam fraksi (E1-E6). Fraksi E4 (250 mg) dilakukan KK $n$ - heksan:MTC 4:6 menghasilkan empat fraksi (E4A-E4D). Fraksi E4C (130 mg) KK $n$ - heksan:EtOAc. Sehingga diperoleh senyawa 2 (E4C2) (66 mg).

\section{Pengujian Senyawa Terhadap Sel MCF-7}

Pengujian sitotoksisitas dilakukan dengan 1 pelat 96 sumuran. Ke dalam tiap sumur dimasukkan suspensi sel dalam medium RPMI 1640 sebanyak 50 $\mu \mathrm{L}$ kemudian diinkubasi selama 24 jam dalam inkubator sel pada suhu $37^{\circ} \mathrm{C}$. Setelah 24 jam, ke dalam sumur uji dimasukkan $50 \mu \mathrm{L}$ larutan uji yang telah dilakukan pengenceran (1 ppm, $10 \mathrm{ppm}, 100$ ppm, $1000 \mathrm{ppm}$, dan $10.000 \mathrm{ppm})$. Setelah itu ditambahkan $10 \mu \mathrm{L}$ kit WST-8 untuk MTT assay kedalam masing masing sumuran dan diinkubasi selama 3 jam. Masukkan pelat kultur 96 sumuran ke dalam ELISA plate reader. Baca serapannya dengan ELISA plate reader pada panjang gelombang $545 \mathrm{~nm}$ dengan referensi $630 \mathrm{~nm}$ (Freshney, R 2005).

\section{HASIL DAN PEMBAHASAN}

Senyawa 1 diperoleh berupa padatan kristal putih, memiliki titik leleh $133,9^{\circ} \mathrm{C}-134,9{ }^{\circ} \mathrm{C}$. Rumus molekul senyawa 1 ditetapkan sebagai $\mathrm{C}_{29} \mathrm{H}_{50} \mathrm{O}$ dengan lima derajat ketidakjenuhan. Spektrum IR (KBr) senyawa 1 menunjukkan pita serapan kuat pada 3424, 2937, 1464, 1379 yang berasal dari regangan $-\mathrm{OH}, \mathrm{C}-\mathrm{H}$ alifatik, $\mathrm{C}=\mathrm{C}$ dan gem dimetil.

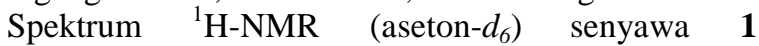
menunjukka lima puluh atom hidrogen dimana terdapat dua sinyal singlet dari metil tersier $\left(\delta_{H} 0,74\right.$ dan 1,02 ppm), tiga sinyal doublet dari metil sekunder $\left(\delta_{H} 0,86 ; 0,84\right.$; dan $\left.0,96 \mathrm{ppm}\right)$, satu sinyal triplet dari metil primer pada $\delta_{H} 0,88 \mathrm{ppm}$, satu proton -OH yang ditunjukkan dengan adanya sinyal berupa puncak lebar pada $\delta_{H} 3,65 \mathrm{ppm}$, satu sinyal proton multiplet yang terikat pada karbon yang mengikat oksigen pada $\delta_{H} 3,39 \mathrm{ppm}$, serta satu sinyal proton olefinik pada $\delta_{H} 5,31 \mathrm{ppm}$. Spektrum ${ }^{13} \mathrm{C}$ NMR (aseton- $d_{6}$ ) menunjukkan 29 atom karbon yang merupakan ciri umum golongan steroid, dua karbon $s p^{2}$, satu karbon $s p^{3}$ teroksigenasi, dan 26 atom karbon $s p^{3}$ lainnya. Adanya sinyal khas yaitu karbon metil pada $\delta_{C} 11-20 \mathrm{ppm}$, satu karbon kuartener $s p^{2}$ pada $\delta_{C} 141,54 \mathrm{ppm}$, satu karbon metin $s p^{2} \delta_{C} 120,74$ ppm menunjukkan bahwa senyawa 1 merupakan steroid stigmastan. Dari data NMR (Tabel 1) senyawa 1 memiliki kerangka steroid stigmastan, $\mathrm{OH}$ yang terikat pada $\mathrm{C}-3$ yang berposisi aksial ( $3 \alpha-)$, serta adanya C-H $s p^{2}$ pada C-5 dan C-6, maka dapat disimpulkan senyawa 1 yang merupakan stigmast-5en-3 $\beta$-ol (Gambar 1).Senyawa $\mathbf{2}$ yang diperoleh berupa padatan kristal putih yang memiliki titik leleh $174,4^{\circ} \mathrm{C}-175,0^{\circ} \mathrm{C}$. Rumus molekul senyawa 2 ditetapkan sebagai $\mathrm{C}_{29} \mathrm{H}_{48} \mathrm{O}$ dengan enam derajat ketidakjenuhan. Spektrum IR $(\mathrm{KBr})$ senyawa 1 menunjukkan pita serapan kuat pada 3424, 2937, 1464, 1379 yang berasal dari regangan $-\mathrm{OH}, \mathrm{C}-\mathrm{H}$ alifatik, $\mathrm{C}=\mathrm{C}$ dan gem dimetil. Spektrum ${ }^{1} \mathrm{H}-\mathrm{NMR}$ dalam $\mathrm{CDCl}_{3}$ menunjukkan senyawa 2 memiliki 48 atom hidrogen dimana terdapat dua sinyal singlet dari metil tersier $\left(\delta_{H} 0,74\right.$ dan $\left.1,02 \mathrm{ppm}\right)$, tiga sinyal doublet dari metil sekunder $\left(\delta_{H} 0,86 ; 0,84\right.$; dan 0,96 ppm), satu sinyal triplet dari metil primer pada $\delta_{H}$ $0,88 \mathrm{ppm}$, satu proton - $\mathrm{OH}$ yang ditunjukkan dengan adanya sinyal berupa puncak lebar pada $\delta_{H} 3,65 \mathrm{ppm}$, satu sinyal proton multiplet yang terikat pada karbon yang mengikat oksigen pada $\delta_{H} 3,53 \mathrm{ppm}$, serta tiga sinyal proton olefinik pada $\delta_{H} 5,35,5,14$, dan 4,76 ppm. Spektrum ${ }^{13} \mathrm{C}$-NMR menunjukkan 29 atom karbon yang terdiri atas dua karbon $s p^{2}$, satu karbon $s p^{3}$ teroksigenasi, dan 26 atom karbon $s p^{3}$ lainnya. Jumlah karbon 29 serta adanya sinyal khas yaitu satu karbon kuartener $s p^{2}$ pada $\delta_{C} 141,54 \mathrm{ppm}$, satu karbon metin $s p^{2} \delta_{C} 120,74$ ppm dan satu karbon metin $s p^{3}$ teroksigenasi pada $\delta_{C} \quad 70,89 \mathrm{ppm}$ menunjukkan bahwa senyawa $\mathbf{2}$ merupakan stigmasterol. Berdasarkan analisis NMR (Tabel 1) dapat diidentifikasikan bahwa senyawa 2 merupakan senyawa stigmasterol (Gambar 1).

Hasil uji sitotoksik senyawa $\mathbf{1}$ dan $\mathbf{2}$ berdasarkan litertur menunjukkan nilai $\mathrm{IC}_{50}$ yang sama yaitu 8,65 $\mu \mathrm{g} / \mathrm{mL}$. Menurut (Cho et al., 1998) nilai $\mathrm{IC}_{50}<5$ $\mu \mathrm{g} / \mathrm{mL}$ dikategorikan sangat aktif, nilai $\mathrm{IC}_{50}$ 6-10 $\mu \mathrm{g} / \mathrm{mL}$ dikategorikan aktif, nilai $\mathrm{IC}_{50} \quad 11-30 \mu \mathrm{g} / \mathrm{mL}$ dikategorikan sedang dan nilai $\mathrm{IC}_{50}>30 \mu \mathrm{g} / \mathrm{mL}$ dikategorikan lemah. 
Tabel 1. Data ${ }^{1} \mathrm{H}$ dan ${ }^{13} \mathrm{C}$ NMR senyawa $\mathbf{1}$ and 2

\begin{tabular}{|c|c|c|c|c|}
\hline \multirow[b]{2}{*}{$\begin{array}{c}\text { Posisi } \\
\text { C }\end{array}$} & \multicolumn{2}{|c|}{ senyawa 1 (stigmast-5-en-3 $\beta$-ol) $*$} & \multicolumn{2}{|c|}{ Senyawa 2 (stigmasterol)** } \\
\hline & ${ }^{13} \mathrm{C}-\mathrm{NMR}$ (ppm) & $\begin{array}{c}{ }^{1} \mathrm{H}-\mathrm{NMR}(\mathbf{p p m}) \\
(\Sigma \mathrm{H}, \text { mult., } J=\mathbf{H z})\end{array}$ & $\begin{array}{c}{ }^{13} \text { C-NMR } \\
\text { (ppm) }\end{array}$ & $\begin{array}{c}{ }^{1} \text { H-NMR(ppm) } \\
(\Sigma H, \text { mult., } J=\text { Hz) }\end{array}$ \\
\hline \multirow[t]{2}{*}{1} & 37,4 & $1,06(1 \mathrm{H}, \mathrm{dd}, 10,5 ; 5,5)$ & 37,4 & $1,05(1 \mathrm{H}, \mathrm{dd}, 10,5 ; 5,5)$ \\
\hline & & $1,11(1 \mathrm{H}, \mathrm{dd}, 10,5 ; 5,5)$ & & $1,11(1 \mathrm{H}, \mathrm{dd}, 10,5 ; 5,5)$ \\
\hline \multirow[t]{2}{*}{2} & 31,7 & $1,69(1 \mathrm{H}, \mathrm{dt}, 9,5 ; 6,0)$ & 32,1 & $1,69(1 \mathrm{H}, \mathrm{dt}, 9,5 ; 6,0)$ \\
\hline & & $1,77(1 \mathrm{H}, \mathrm{dt}, 9,5 ; 6,0)$ & & $1,83(1 \mathrm{H}, \mathrm{dt}, 9,5 ; 6,0)$ \\
\hline 3 & 70,9 & $3,39(1 \mathrm{H}, \mathrm{m}, 3,8)$ & 72,0 & $3,53(1 \mathrm{H}, \mathrm{m})$ \\
\hline 4 & 42,5 & $2,21(2 \mathrm{H}, \mathrm{d}, 6,5)$ & 42,4 & $2,23(2 \mathrm{H}, \mathrm{d}, 6,5)$ \\
\hline 5 & 141,5 & - & 140,9 & - \\
\hline 6 & 120,7 & $5,31(1 \mathrm{H}, \mathrm{d}, 4,9)$ & 120,7 & $5,31(1 \mathrm{H}, \mathrm{d}, 4,9)$ \\
\hline 7 & 31,8 & $1,94(2 \mathrm{H}, \mathrm{dt}, 5,6 ; 8,5)$ & 31,8 & $1,97(2 \mathrm{H}, \mathrm{dt}, 5,6 ; 8,5)$ \\
\hline 8 & 36,2 & $1,42(1 \mathrm{H}, \mathrm{m})$ & 31,8 & $1,43(1 \mathrm{H}, \mathrm{m})$ \\
\hline 9 & 50,4 & $0,95(1 \mathrm{H}, \mathrm{m})$ & 50,3 & $0,95(1 \mathrm{H}, \mathrm{m})$ \\
\hline 10 & 36,5 & - & 36,6 & - \\
\hline 11 & 20,9 & $1,55(2 \mathrm{H}, \mathrm{m})$ & 21,3 & $1,50(2 \mathrm{H}, \mathrm{m})$ \\
\hline 12 & 39,8 & $1,19(2 \mathrm{H}, \mathrm{d}, 5,6)$ & 39,9 & $1,17(2 \mathrm{H}, \mathrm{d}, 5,6)$ \\
\hline 13 & 42,3 & - & 42,5 & - \\
\hline 14 & 56,8 & $1,13(1 \mathrm{H}, \mathrm{m})$ & 56,9 & $1,13(1 \mathrm{H}, \mathrm{m})$ \\
\hline 15 & 25,9 & $1,23(2 \mathrm{H}, \mathrm{m})$ & 24,5 & $1,23(2 \mathrm{H}, \mathrm{m})$ \\
\hline 16 & 28,1 & $1,95(2 \mathrm{H}, \mathrm{m})$ & 29,3 & $1,97(2 \mathrm{H}, \mathrm{m})$ \\
\hline 17 & 56,1 & $1,15(1 \mathrm{H}, \mathrm{m})$ & 56,2 & $1,15(1 \mathrm{H}, \mathrm{m})$ \\
\hline 18 & 11,5 & $0,97(1 \mathrm{H}, \mathrm{m})$ & 40,7 & $0,78(3 \mathrm{H}, \mathrm{m})$ \\
\hline 19 & 18,4 & $0,96(3 \mathrm{H}, \mathrm{d}, 6,7)$ & 21,3 & $1,02(3 \mathrm{H}, \mathrm{t}, 1,89)$ \\
\hline 20 & 40,6 & $2,05(2 \mathrm{H}, \mathrm{m})$ & 138,5 & 4,76 (1H, m) \\
\hline 21 & 19,3 & $1,27(2 \mathrm{H}, \mathrm{m})$ & 129,4 & $5,14(1 \mathrm{H}, \mathrm{m})$ \\
\hline 22 & 33,9 & $1,22(1 \mathrm{H}, \mathrm{m})$ & 46,0 & $2,02(2 \mathrm{H}, \mathrm{m})$ \\
\hline 23 & 24,1 & $1,6(2 \mathrm{H}, \mathrm{m})$ & 25,6 & $1,58(2 \mathrm{H}, \mathrm{m})$ \\
\hline 24 & 45,9 & $0,88(3 \mathrm{H}, \mathrm{t}, 7,1)$ & 12,2 & $0,83(1 \mathrm{H}, \mathrm{m})$ \\
\hline 25 & 31,9 & $1,15(1 \mathrm{H}, \mathrm{m})$ & 29,3 & $1,15(1 \mathrm{H}, \mathrm{m})$ \\
\hline 26 & 18,9 & $0,86(3 \mathrm{H}, \mathrm{d}, 6,2)$ & 20,0 & $0,81(3 \mathrm{H}, \mathrm{d}, 6,2)$ \\
\hline 27 & 18,5 & $0,84(3 \mathrm{H}, \mathrm{d}, 6,2)$ & 19,5 & $0,80(3 \mathrm{H}, \mathrm{d}, 6,7)$ \\
\hline 28 & 22,9 & $0,74(3 \mathrm{H}, \mathrm{s})$ & 18,9 & $0,67(3 \mathrm{H}, \mathrm{s})$ \\
\hline 29 & 11,4 & $1,02(3 \mathrm{H}, \mathrm{s})$ & 12,2 & $1,02(3 \mathrm{H}, \mathrm{s})$ \\
\hline
\end{tabular}

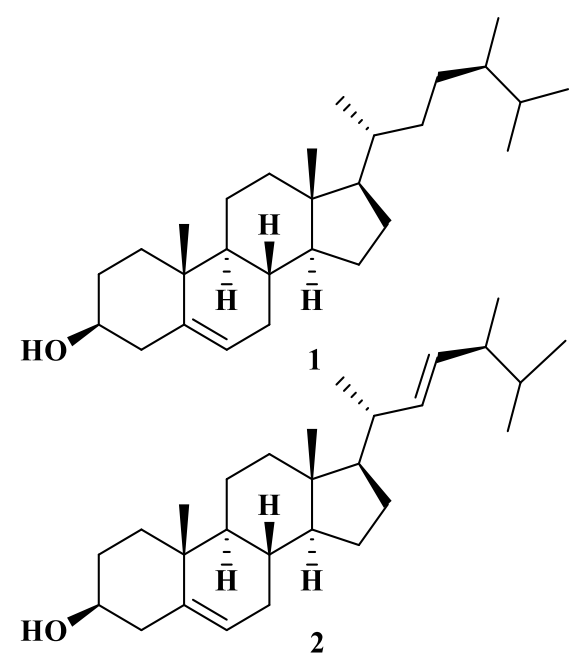

Gambar 1. Stigmast-5-en-3ß-ol (1) stigmasterol (2)

\section{KESIMPULAN}

Hasil isolasi ekstrak $n$-heksan kulit batang $D$. alliaceum didapatkan dua senyawa golongan steroid yaitu stigmast-5-en-3 $\beta$-ol (1) dan stigmasterol (2) dimana keduanya aktif terhadap sel kanker payudara MCF-7 dengan nilai $\mathrm{IC}_{50} 8,65 \mu \mathrm{g} / \mathrm{mL}$.

\section{Ucapan Terima Kasih}

Ungkapan rasa terima kasih kepada LIPI untuk pengukuran NMR dan juga kepada Lab Kultur dan Jaringan Eyckman untuk uji aktivitas sitotoksik MCF-7, dana penelitian berasal dari dana tesis dan disertasi LPDP.

\section{DAFTAR PUSTAKA}

Cho, R.J., Fromont-Racine, M., Wodicka, L., Feierbach, B., Stearns, T., Legrain, P., Lockhart, D.J., \& Davis, R.W. (1998). Parallel analysis of genetic selections using whole genome oligonucleotide arrays. Proc.Natl. Acad.Sci.USA, 95, 3752-3757.

Freshney, R, I., (2005). Culture of Animal Cells: A Manual of Basic Technique Fifth Edit., 
Newyork: Oxford Universit Press.

Lakshmi, V., Pandey, K., Kapil, A., Singh, N., Samant, M., \& Dube, A. (2007). In vitro and in vivo leishmanicidal activity of Dysoxylum binectariferum and its fractions against Leishmania donovani. Phytomedicine, 14(1), 36-42.

Mabberley, D.J., (2008). 14. Dysoxylum Blume, Bijdr. 172. 1825. FI.China, 11, 125-129.

Mohanakumara, P.1., Sreejayan, N., Priti, V., Ramesha, B.T., Ravikanth, G., Ganeshaiah, K.N., Vasudeva, R., Mohan, J., Santhoshkumar, T.R., Mishra, P.D., Ram, V, \& Shaanker, R.U. (2010). Dysoxylum binectariferum Hook.f (Meliaceae), a rich source of rohitukine. Fitoterapia, 81(2), 145148.

Najmuldeen, I.A., (2011). Phytochemical Studies And The Bioactivities Of Three Meliaceae Species, Thesis, University of Malaya, Kuala Lumpur.
National Cancer Institute, (2012). What You Need To Know about reast Cancer. In pp. 11-29.

Nishizawa, M., Inoue, A., Sastrapradja, S., \& Hayashi, Y. (1982). (+)-8hydroxycalamennene: a fish-poison principle of Dysoxylum acutangulum and D. alliaceum., Phytochemistry, 22 (1). 2083-2085.

Tobin, G., Kalupahana, R. \& Kulka, M., (2012). Plant Based Natural Products and Breast Cancer: Considering Multi-Faceted Disease Aspects , Past Successes , and Promising Future Interventions, In. M. Kulka (Ed.). Using Old Solutions to New Problems - Natural Drug Discovery in the 21st Century. pp. 30-40.

Wink, M., Ashour, M.L. \& El-Readi, M.Z., (2012). Secondary metabolites from plants inhibiting $\mathrm{ABC}$ transporters and reversing resistance of cancer cells and microbes to cytotoxic and antimicrobial agents. Frontiers in Microbiology, 3. 1-15. 